\title{
Comparative study of control selection in a national population -based case-control study: Estimating risk of smoking on cancer deaths in Chinese men
}

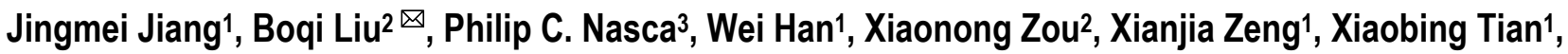 \\ Yanping $\mathrm{Wu}^{2}$, Ping $\mathrm{Zhao}^{2}$, Junyao $\mathrm{Li}^{2}$
}

1. Department of Epidemiology and Medical Statistics, Peking Union Medical College

2. Department of Epidemiology, National Cancer Institute, Chinese Academy of Medical Sciences

3. Department of Epidemiology and Biostatistics, SUNY, Albany, the USA

$\triangle$ Correspondence to: Professor Boqi Liu, 17 Pan Jia Yuan Nan Li, Beijing (100021), National Cancer Institute, Chinese Academy of Medical Sciences, China. Tel: 86-10-87788441; Fax: 86-10-85370653; E- mail address: wangjbo@263.net

Received: 2009.08.04; Accepted: 2009.10.20; Published: 2009.10.28

\begin{abstract}
Purpose: To assess the validation of a novel control selection design by comparing the consistency between the new design and a routine design in a large case-control study that was incorporated into a nationwide mortality survey in China.

Methods: A nationwide mortality study was conducted during 1989-1991. Surviving spouses or other relatives of all adults who died during 1986-1988 provided detailed information about their own as well as the deceased person's smoking history. In this study, 130,079 males who died of various smoking-related cancers at age 35 or over were taken as cases, while 103,248 male surviving spouses (same age range with cases) of women who died during the same period and 49,331 males who died from causes other than those related to smoking were used as control group I and control group 2, respectively. Consistency in the results when comparing cases with each of the control groups was assessed.

Results: Consistency in the results was observed in the analyses using different control groups although cancer deaths varied with region and age. Equivalence could be ascertained using a 15\% criterion in most cancer deaths which had high death rates in urban areas, but they were uncertain for most cancers in rural areas irrespective of whether the hypothesis testing showed significant differences or not.

Conclusions: Sex-matched living spouse control design as an alternative control selection for a case-control study is valid and feasible, and the basic principles of the equivalence study are also supported by epidemiological survey data.
\end{abstract}

Key words: case-control studies; epidemiologic methods; comparative study; smoking; Chinese men.

\section{Introduction}

One of the most important measures for ascertaining the impact of tobacco on a population is the estimation of the mortality attributable to its use. To measure this, a number of indirect methods of quantification are available. ${ }^{1-5}$ However, although different methodologies are widely used, their methodological foundations are all quite similar. Mainly they are based on the calculation of the proportional attributable fraction. Thus, one of the limitations of the estimation remained, because the proportional mortality 
analysis cannot estimate mortality from the causes of death similar to those in the reference group. To improve the existing calculations, a novel control group design was introduced in a previous study, ${ }^{6}$ which replaced the regular reference group by using the same sex surviving spouses of deceased people to calculate the mortality risk rate. However, one question has been raised simultaneously, is it accurate and validation?

Although most clinical study activities are aimed at showing that equivalence can also be claimed for generic versions of innovator drugs and for such diverse entities as medical protocols, surgical techniques and medical devices, $7-10$ there are no such standard criteria for how to evaluate and support such equivalence claim in epidemiological survey data although many reports, ${ }^{11-13}$ for example, suggested that several well-designed valid case-control studies with consistent results should be helpful in policy making when an answer is needed a short time.

The purpose of this study was to apply the basic principles of a population-based case-control study to assess the validation of the novel control selection design by comparing the consistency between the new design and a routine control selection design in a large case-control study that was incorporated into a nationwide mortality survey in China in 1989-1991. As an example, we assessed the hazards of tobacco use on smoking-related cancer deaths in Chinese adult men. We also offer specific suggestions that we believe are useful in choosing controls within the framework of the study principles.

\section{SUBJECTS AND METHODS}

\section{National Mortality Survey and Case-Control Study Design}

In 1989-1991, a large nationwide retrospective mortality survey was conducted in China, which involved 103 study areas (24 major cities and 79 counties) and approximately 1,000,000 adult deaths from all causes during the years 1986-1988. ${ }^{1}$ We defined the total population (close to 67 million) from which the mortality survey was conducted as the study base. Cases and two groups of controls were obtained within the study base: 130,079 males who died of smoking-related cancers at age 35 or over were defined as cases. These diseases included: malignant neoplasm of the lips, oral cavity, and larynx ((ICD-9: $140-149,161,3.9 \%)$, esophageal cancer (150, 15.2\%), stomach cancer $(151,25.9 \%)$, liver cancer $(155,22.7 \%)$, lung cancer $(162,27.2 \%)$, pancreatic cancer $(157,2.6 \%)$, prostate cancer $(185,0.7 \%)$, and bladder cancer (188, $1.8 \%)$ ). We combined the cancers of ICD-9 Codes
$(140-149,161)$ into one group named "minor site cancers" because the death rates for these cancers were too low for separate analysis. Two different control groups were selected. The first group was recruited using the novel design, which comprised all male surviving spouses (same age range with cases) of any women who died (any cause of death) during those same years. The second control group was chosen using the proportional mortality method and comprised all men aged 35 or over who died from causes other than those related to smoking. These diseases included: infectious and parasitic diseases (ICD-9: 001-009, 020-139, 7.8\%), endocrine, metabolic, immune diseases (240-279, 5.6\%), blood and blood-forming organ diseases (280-289, 0.9\%), mental disorders (290-319, 3.3\%), nervous system diseases $(320-359,3.1 \%)$, digestive system diseases (520-579, $27.5 \%)$, genitourinary system diseases (580-608, $10.0 \%)$, musculoskeletal and connective tissue diseases $(710-739,0.9 \%)$, injury and poisoning (800-897, $33.1 \%)$, and other medical disorders (360-389, $680-709,780-796,7.9 \%)$. The selection of controls in this study was based on three assumptions: (1) the individuals in both control groups had, in 1980, smoking habits that were similar to those of the study base; (2) there was no significant relationship between husband and wife in control group 1 in terms of tobacco use; (3) the causes of death in control group 2 were unrelated to tobacco exposure. Thus two separate population-based case-control studies were formed within the study base with one group of cases and two different control groups.

The information on smoking history was obtained by interviews. We interviewed informants (spouses or other relatives) of all deceased persons who described their own smoking habits as well as those of their dead partners. These data were used to determine whether people had ever smoked before 1980, a period of time prior to the onset of their disease. A non-smoker was defined as a person who had never smoked during his life or had only smoked infrequently at a young age.

\section{Statistical Methods}

The relative risk (RR) for cancer deaths in smokers and non-smokers was estimated by non-conditional logistic regression, adjusted for age (5-year age groups) and the area of the residence.

Confidence intervals (CIs) were used in this study, as in clinical trials, ${ }^{7-10}$ to evaluate the equivalence of the two case-control studies in assessing the risk of cancer deaths due to smoking. We first defined a range of equivalence as an interval from $-\delta$ to $\delta$ (here, we defined $\delta=0.15$ ). We then simply checked 
whether the $\mathrm{CI}$ centered on the observed ratio of $\frac{R \hat{R}_{1}}{R \hat{R}_{2}}$ (the procedure of calculating $\mathrm{CI}$ is listed in Appendix) lay entirely between $\mathrm{e}^{-\delta}$ to $\mathrm{e}^{+\delta}$. If it did, equivalence was demonstrated; if it did not, there was uncertainty regarding equivalence. Because $e^{\delta} \cong 1+\delta$ (when $\delta \leq 0.15$ ), for convenience, the range of equivalence was replaced by $(1-\delta, 1+\delta)$. Thus the limits for equivalence in this study were within 0.85 and 1.15 .

\section{RESULTS}

There were a total of 130,079 cases and 152,579 controls $(103,248$ in control group $1 ; 49,331$ in control group 2) in our study. The basic characteristics of the cases and controls, and relative risk of smoking-related cancer deaths among smokers by comparison cases with each of the two control groups are shown in Table 1. Although data show that the relative risk from smoking was greater for urban males than rural males, both study groups revealed a consistent pattern of the effect of smoking on risk of cancer deaths.

TABLE I. Characteristics of cases and two control groups: Population-based case-control study of smoking on risk of cancer deaths among Chinese men 1989-1991.

\begin{tabular}{|c|c|c|c|}
\hline \multirow[t]{2}{*}{ Characteristic } & \multirow[t]{2}{*}{ Cases } & \multicolumn{2}{|l|}{ Controls } \\
\hline & & $\begin{array}{l}\text { Control } \\
\text { group } 1\end{array}$ & $\begin{array}{l}\text { Control } \\
\text { group } 2\end{array}$ \\
\hline No. of subjects & 130,079 & 103,248 & 49,331 \\
\hline Mean age (years) & $63.3 \pm 10.7 \dagger$ & $62.4 \pm 11.6$ & $61.0 \pm 13.8$ \\
\hline$\%$ urban & 69.2 & 69.1 & 24.6 \\
\hline$\%$ rural & 30.8 & 30.9 & 75.4 \\
\hline \% smokers (Total) & 70.7 & 59.2 & 63.4 \\
\hline $\begin{array}{l}\mathrm{n}, \% \text { smokers (Ur- } \\
\text { ban) }\end{array}$ & $90,061(70.1)$ & $\begin{array}{l}71,316 \\
(57.1)\end{array}$ & $12,147(58.4)$ \\
\hline $\begin{array}{l}\text { n, \% smokers (Ru- } \\
\text { ral) }\end{array}$ & $40,018(71.9)$ & $\begin{array}{l}31,932 \\
(64.1)\end{array}$ & $37,184(65.1)$ \\
\hline \multicolumn{4}{|c|}{$\begin{array}{l}\text { Relative Risk }(95 \% \mathrm{CI}) \ddagger \text { for smoking } \\
\text { with cases and different controls }\end{array}$} \\
\hline Urban & $1.77(1.73-1.81)$ & \multicolumn{2}{|c|}{$1.71(1.65-1.78)$} \\
\hline Rural & $1.44(1.41-1.49)$ & \multicolumn{2}{|c|}{$1.37(1.33-1.45)$} \\
\hline \multicolumn{4}{|c|}{$\%$ of deaths attributed to smoking } \\
\hline Urban & $30.5 \%$ & \multicolumn{2}{|l|}{$29.1 \%$} \\
\hline Rural & $21.9 \%$ & \multicolumn{2}{|l|}{$19.4 \%$} \\
\hline
\end{tabular}

† One standard deviation

‡ 95\% confidence interval

Overall, $35.6 \%$ of the cancer cases (38.5\% urban, $28.9 \%$ rural) were confirmed by pathology, 56.3\% (55.8\% urban, $57.5 \%$ rural) were diagnosed by X-ray or by CT scan, and $8.1 \%$ (5.7\% urban, $13.5 \%$ rural) were diagnosed by clinical experience or by other methods. The other methods group included patients who could not afford to go to hospital, and when the families of these individuals were interviewed, a qualified physician provided a diagnosis based on the patient's symptoms.

The adjusted cancer RRs and their CIs had a high degree of overlap (with a small standard error) between the two control groups in deaths from esophagus cancer, stomach cancer, liver cancer, and lung cancer (Figure 1) which had high incidence rates although the death rates from these cancers varied by region and age (data not shown). When data were combined to calculate the risk for all men, the RR $(95 \% \mathrm{CI})$ with control groups one and two, respectively, were: 1.96 (1.84-2.08) and 1.88 (1.79-1.97) for esophagus cancer; 1.29 (1.23-1.35) and 1.28 (1.24-1.34) for stomach cancer; 1.35 (1.31-1.39) and 1.33 (1.27-1.39) for liver cancer, 2.98 (2.88-3.08) and 2.95 (2.81-3.09) for lung cancer. However, for other neoplasms which had low rates, the discrepancies in CIs were increased because of a large standard error, and this was particularly true for rural residents.

The relative risks for cancer deaths between the two groups were also examined in subgroups according to smoking history (Figure 2-3). The result revealed a high consistency with both control groups in most subgroups. In particular, with smokers in both urban and rural areas, whose most recent habits involved only cigarettes, significant dose-response relationships were found both in the duration of the smoking habit and in daily cigarette consumption. For example, in urban men, the RR $(95 \% \mathrm{CI})$ for daily cigarette consumption $<10,10-19, \geq 20$ cigarettes per day, respectively were: study group $1: 1.40$ (1.34-1.45), 1.48 (1.44-1.52), and 2.25 (2.19-2.32); study group 2: 1.38 (1.29-1.49), 1.42 (1.35-1.50), and 2.12 (2.01-2.22). The absolute differences between the two groups in RRs ranged from 0.02 to 0.13 . Furthermore, the RR $(95 \% \mathrm{CI})$ for those who smoked $\geq 20$ cigarettes each day and had been smoking of for <20, 20-34, and 35+ years, respectively, were: group 1: 1.73 (1.65-1.82), 2.26 (2.16-2.36) and 2.53 (2.45-2.62); group 2: 0.98 (0.90-1.06), 1.94 (1.78-2.12) and 3.06 (2.85-3.28). The absolute differences in RRs ranged from 0.32 to 0.75 , respectively (all trends test, $P<0.001$ ). There was a similar trend in rural men, although the RRs were smaller than in urban men.

The equivalence tests with a predefined interval (0.85-1.15) for various cancer deaths were shown in Figure 4, and the importance of not basing conclusions on statistical significance can also be seen in this Figure. Any CI which does not overlap 1.0 corresponds to a statistically significant difference between the two control groups. In the data shown for urban males, the two estimates could be considered to have 
equivalence in esophagus cancer, stomach cancer, liver cancer, pancreas cancer, lung cancer cancers, and cancers on the minor sites, whereas the equivalence is uncertain for bladder cancer and prostate cancer although all showed no statistically significant difference between compared groups. For rural males, no equivalence could be ascertained (except for liver cancer deaths) irrespective of whether the hypothesis testing showing significant differences or not. Furthermore, when we combined all cancers to test equivalence again, the results revealed equivalence in the two control groups for both urban and rural males, with no statistically significant difference in total cancer deaths between the compared groups.

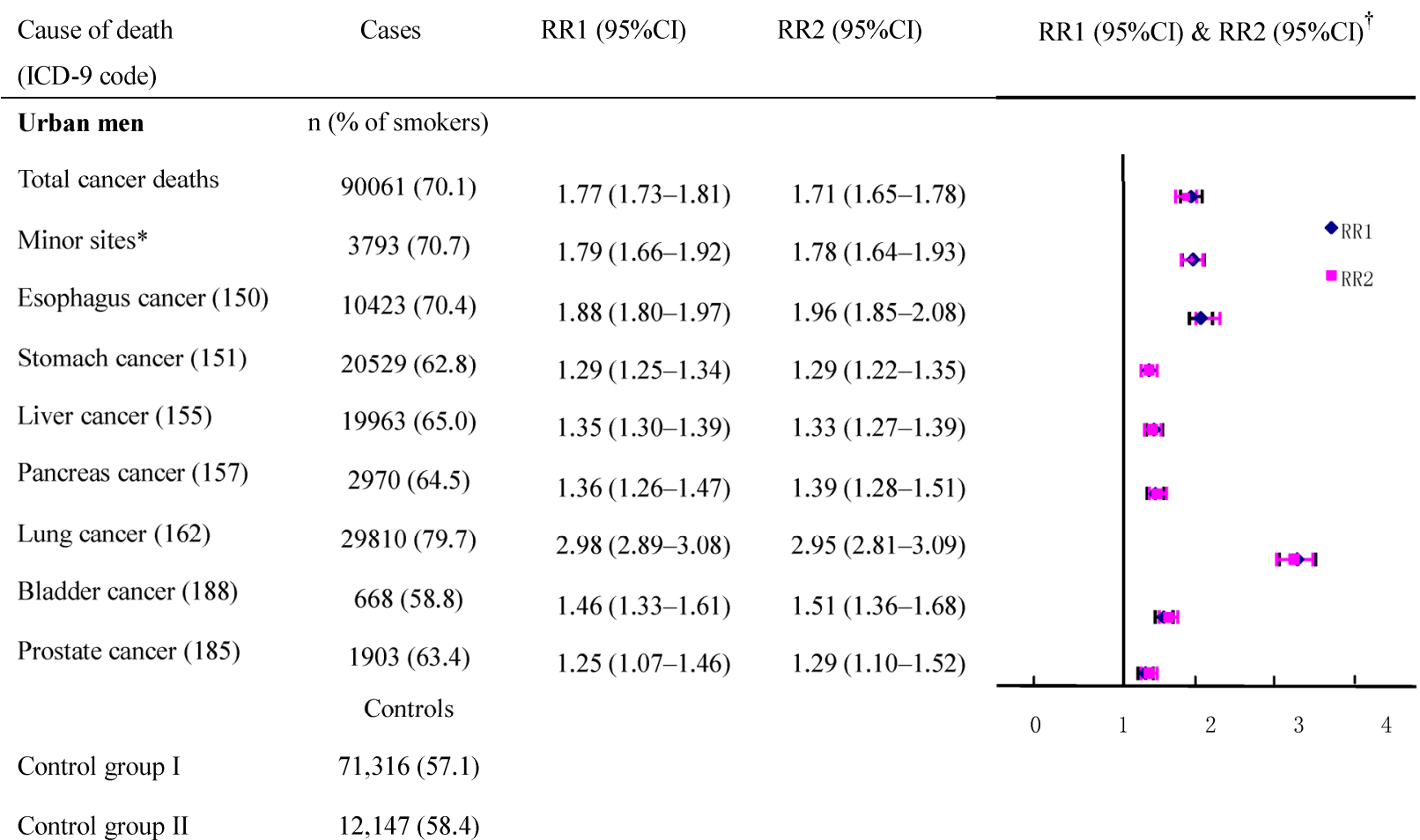

\section{Rural men}

$\begin{array}{lr}\text { Total cancer deaths } & 40018(71.9) \\ \text { Minor sites* } & 1332(73.4) \\ \text { Esophagus cancer (150) } & 9304(71.4) \\ \text { Stomach cancer (151) } & 13181(68.5) \\ \text { Liver cancer (155) } & 9548(70.9) \\ \text { Pancreas cancer (157) } & 425(72.2) \\ \text { Lung cancer (162) } & 5578(82.2) \\ \text { Bladder cancer (188) } & 197(67.0) \\ \text { Prostate cancer (185) } & 453(69.1) \\ & \text { Controls } \\ \text { Control group I } & 31,932(64.1) \\ \text { Control group II } & 37,184(65.1)\end{array}$

FIGURE I. Smoker vs. non-smoker cancer death RR ratios in various cancer sites in males ages 35 and over, 1986-1988 in urban and rural areas. $\nmid R R I$ and RR2 denote relative risks calculated with study groupl and study group 2, respectively. 


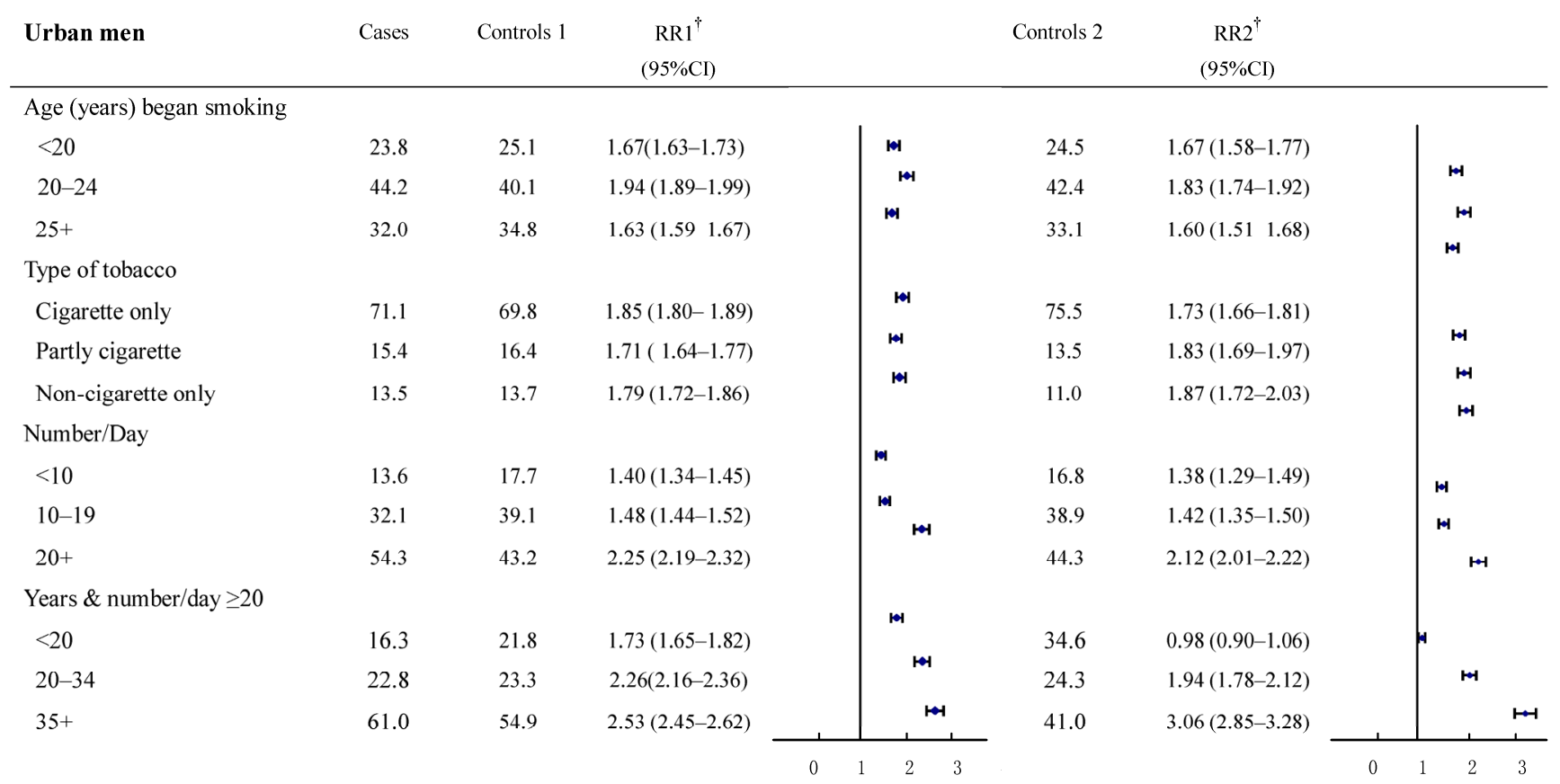

FIGURE 2. Proportion of smoking by different smoking histories and relative risk for smoker vs. non-smoker cancer death in various subgroups. Urban males ages 35 and over, 1986-1988 in China. $\nmid$ RRI and RR2 denote relative risks calculated with study groupl and study group 2 , respectively.

\begin{tabular}{|c|c|c|c|c|c|c|c|}
\hline Rural men & Cases & Controls 1 & $\begin{array}{c}\text { RR1 } \\
(95 \% \mathrm{CI}) \\
\end{array}$ & & Controls 2 & $\begin{array}{c}\text { RR2 } \\
(95 \% \mathrm{CI}) \\
\end{array}$ & \\
\hline \multicolumn{8}{|c|}{ Age (years) began smoking } \\
\hline$<20$ & 21.5 & 20.7 & $1.49(1.421-57)$ & 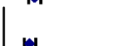 & 22.1 & $1.34(1.28-1.40)$ & m \\
\hline $20-24$ & 45.6 & 46.4 & $1.41(1.36-1.47)$ & 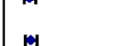 & 46.9 & $1.33(1.28-1.38)$ & m \\
\hline $25+$ & 32.9 & 32.9 & $1.43(1.37-1.48)$ & & 30.9 & $1.45(1.40-1.51)$ & m \\
\hline \multicolumn{8}{|l|}{ Type of tobacco } \\
\hline Cigarette only & 37.8 & 37.0 & $1.58(1.52-1.65)$ & a & 32.1 & $1.69(1.63-1.76)$ & 101 \\
\hline Partly cigarette & 34.4 & 29.0 & $1.70(1.63-1.77)$ & 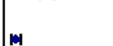 & 30.7 & $1.51(1.45-1.57)$ & 191 \\
\hline Non-cigarette only & 27.8 & 34.0 & $1.17(1.12-1.22)$ & & 37.2 & $1.02(0.98-1.07)$ & - \\
\hline \multicolumn{8}{|l|}{ Number/Day } \\
\hline$<10$ & 13.3 & 15.7 & $1.34(1.26-1.42)$ & m & 15.8 & $1.30(1.22-1.38)$ & $m$ \\
\hline $10-19$ & 40.2 & 43.4 & $1.48(1.41-1.54)$ & 19 & 39.7 & $1.57(1.51-1.64)$ & 191 \\
\hline $20+$ & 46.5 & 40.9 & $1.83(1.76-1.92)$ & m & 44.5 & $1.64(1.57-1.70)$ & 191 \\
\hline \multicolumn{8}{|c|}{ Years \& number/day $\geq 20$} \\
\hline$<20$ & 40.6 & 50.1 & $1.45(1.37-1.53)$ & m & 54.4 & $1.22(1.15-1.28)$ & $m$ \\
\hline $20-34$ & 26.6 & 24.9 & $1.92(1.78-2.06)$ & Her & 21.3 & $2.05(1.97-2.20)$ & 191 \\
\hline $35+$ & 32.8 & 25.1 & $2.34(2.18-2.51)$ & ror & 24.2 & $2.26(2.18-2.42)$ & For \\
\hline
\end{tabular}

FIGURE 3. Proportion of smoking by different smoking histories and relative risk for smoker vs. non-smoker cancer death in various subgroups. Rural males ages 35 and over, 1986-1988 in China. 

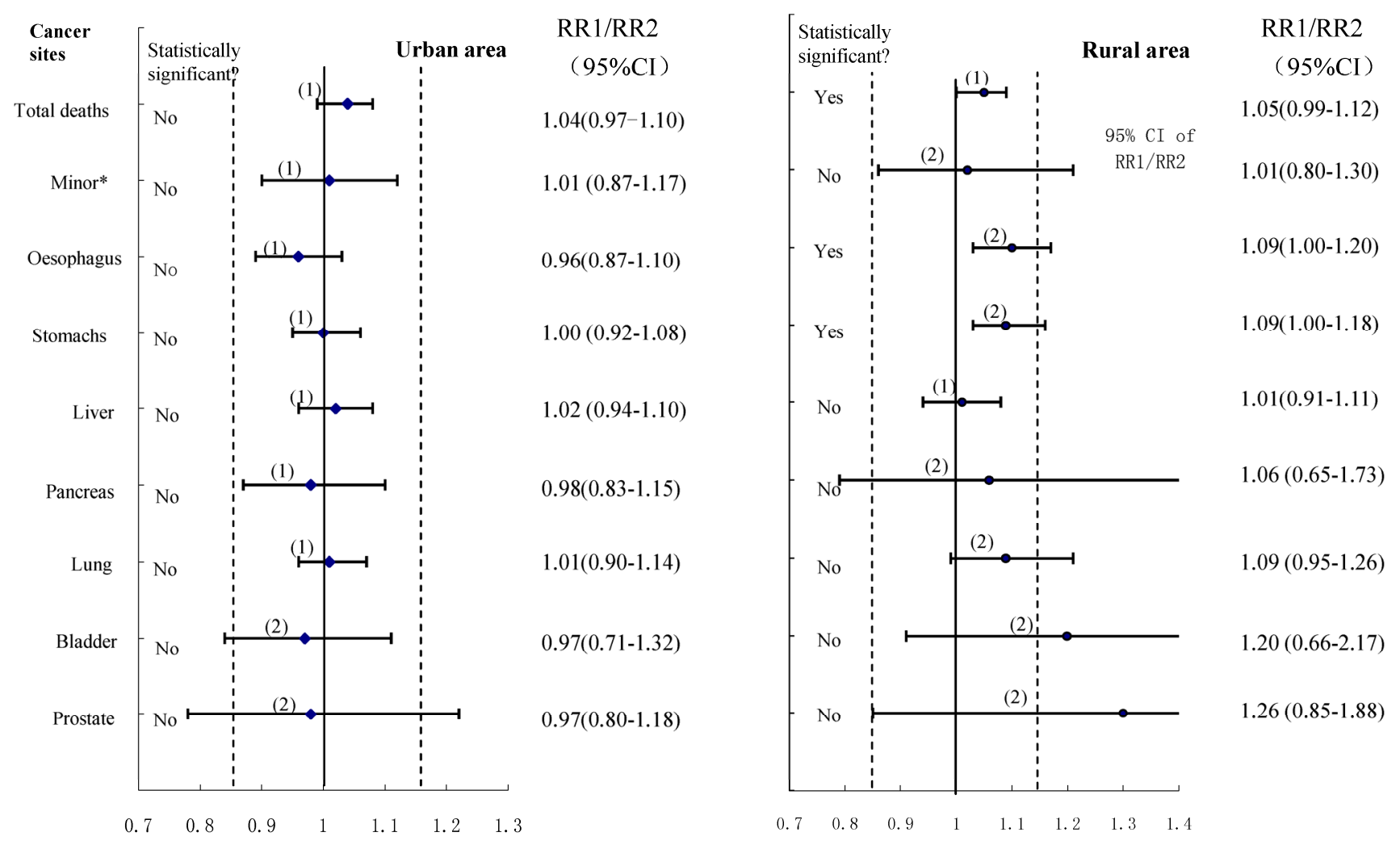

FIGURE 4. The results of using the confidence interval approach: $-\delta(I 5 \%)$ to $+\delta$ is the pre-specified range of equivalence: the horizontal lines correspond to possible outcomes expressed as confidence intervals, with the associated significance test results shown on the left: (I) denotes equivalence; (2) denotes uncertainty.

\section{Discussion}

To our knowledge, this is the first nationwide study comparing different control groups in a population-based case-control study, to assess the association between smoking and death from various cancers in Chinese men. It shows that tobacco smoking is associated with a moderate, but highly significant, increase in the risk of death from various cancers. The consistency in results was observed in the analyses using different control groups although in most cases the value of RR1 revealed a bit greater than the value of RR2. Our study showed that equivalence can be ascertained using the $15 \%$ criterion in those cancers which are very common in urban areas, but they are uncertain for most cancers in rural areas irrespective of whether the hypothesis testing showed significant differences or not between the two control groups.

Using sex-matched spouses as controls is an innovative design, and it is possible to produce approximately random samples of the base population, because all deceased people were approximately at random within the study base, as were their spouses. The strengths of this design are: (1) it is possible to provide an alternative method to give accurate esti- mate of early smoking-attributable mortality within a nationwide level; (2) we may assess more relationships between one or more exposures and various causes of death at one time, and use of a single control group for more than one case series can lead to saving of money and time; ${ }^{11-12}$ (3) all possible confounding factors (known or unknown) and interaction effects between groups are balanced by using large matching populations. In contrast, prospective studies take years to mature, whereas retrospective methods require much less time. ${ }^{12}$

Three issues have been considered regard with the valid of our results: First, it should be noted, if there is a strong association of smoking habits between couples, the risks may be somewhat attenuated. In this study, the Kappa coefficient of agreement test on smoking habits of couples were 0.076 in urban areas, and 0.163 in rural areas, indicating a very weak association between couple's smoking habit. Second, we compared the prevalence of smoking between male living spouses of women who died of any cause and those spouses of women who died of some other causes other than smoking related causes. The prevalence of smoking were $57.1 \%$ and $57.8 \%$, respectively, for urban male spouses, $64.1 \%$ and $63.6 \%$, respectively 
for rural male spouses indicating the relative risk analyses will not exaggerate the hazard of tobacco. The third issue involves the validity of smoking data obtained from surrogates. There are few former smokers in China (except those who stopped because they were ill), ${ }^{14-16}$ and family members were generally confident about whether the dead person had smoked, although they were sometimes uncertain of the age when smoking began. A validity study in Shanghai was conducted where the surviving spouse was the informant and both husband and wife had reported their smoking habits in the early 1980s. ${ }^{17}$ Information obtained from the spouse on the husband's smoking habits was highly consistent with information provided directly by the husband. In this study, the very similar trends exit between two groups in different subgroups (Figure 2-3) indicating there is no obvious disagreement in smoking history reported by proxy or by self-report.

In this study, we attempt to apply the equivalence approach to assess the consistency of different control selections with a control group determined by the proportional mortality method as an 'active control' to evaluate the accuracy and feasibility of the new control design. Although the dependence of RR1 and RR2 may have some extended the length of CIs, which could lower the precise of CIs, some strengths are still addressed:7,13,18 First, a large adequate sample size in each compared group can insure consistency between the initial design and final analysis based on symmetric CIs for estimation using a normal CI approach. Second, a large adequate sample size in each compared group will make a high probability $(1-\beta, \beta$ is type II error) to insure that the upper/low limit of CIs will not excess the selected criterion $( \pm 15 \%)$, i.e.,

$\operatorname{Pr}\left[\left(\ln O \hat{R}_{1}-\ln O \hat{R}_{2}+z_{1-\alpha} \sqrt{\operatorname{Var}\left(\ln O \hat{R}_{1}-\ln O \hat{R}_{2}\right.}\right) \leq \delta\right]=1-\beta$ , where $1-\beta$ is statistical power. ${ }^{19}$ Third, we selected control group 2 as an 'active control' group which is reliant on an implicit 'historical control assumption'. One cannot automatically assume that the active control group will be effective under a new set of study conditions by virtue of the fact that it was previously proven to be efficacious for a given indication. Our findings revealed that better equivalence exists in urban than in rural areas, and for cancers with a high death rate than for 'rare' cancers. The possible explanations may be: (1) some rare cancer death rates are too low to be stable; (2) a difference in the accuracy of certificated cause of death between urban and rural counties; (3) large fluctuations in Chinese social circumstances during the decades before 1980, with large changes in cigarette sales per adult, meaning that middle-aged cigarette smokers who died in 1986-1988 were unlikely to have had consistent tobacco consumption since early adult life: this is particularly true in large rural areas. Our findings also confirmed the fact that the conventional statistical significance test has little relevance in equivalence testing. Failure to detect a difference between two RRs does not imply equivalence, and a statistically significant difference does not mean it is not equivalent. It should be noted that absolute equivalence can never be demonstrated, and it is only possible to assert that the true difference is unlikely to be outside a range, which depends on the size of the trial and specified probabilities of error.13,18

In the methodological areas of control selection, it is widely accepted that the inclusion of multiple control groups selected by different criteria is preferable to only one control group. ${ }^{20-23}$ Multiple control groups provide checks on potential biases, and afford the opportunity to demonstrate consistency in the findings. In our study, a series of consistent patterns of results was obtained from control group 1 and group 2. Although selection biases could produce similar but erroneous results, this is most unlikely because two control groups were selected by completely different means in this study. However, it should be noted that there is no 'gold standard' in epidemiological surveys although we selected controls by the proportional mortality method as the 'active controls.' Any control selection has its own strength or weakness. We used the proportional mortality method, for example, to create an 'active control,' and the main strengths of such controls is that the criteria for eligible controls can be established conveniently; any omissions typically will not lead to selection bias, since the accuracy of the system for registering deaths from most causes is unlikely to vary substantially with cause of death. ${ }^{11,18}$ Furthermore, any recall bias affecting assessment of smoking habits in the cases should similarly affect assessment of smoking habits in the control group, ${ }^{1}$ however, insisting on a dead control group violates the study base principle, since the base consists of living subjects. In the same situation, when we use a sex-matched living spouse control design, we may explore smoking hazards more widely (known or unknown) and accurately. However, when information is obtained from a surrogate because the case is dead, using a living control sampled properly from the base can breach the principle of comparable accuracy. ${ }^{11}$

Some limitations of this study must also be considered when interpreting the results. First, only $90 \%$ of deaths in the study base were recruited, thus selec- 
tion bias may have some effect on our results. Second, $5.7 \%$ of urban and $13.5 \%$ of rural cancer deaths in our study were diagnosed only by clinical experience, or inference after dying, which may result in misclassification, and this is particularly true in rural areas, although our design included a greater urban population than rural population, which countered the difference in accuracy of the death certificate. Third, social class, which is also associated with both smoking and cancer deaths, was not measured in this study, and the separate calculation of risk patterns in urban and rural areas was used as a surrogate analysis by socioeconomic status.

In conclusion, the basic principles of equivalence are also supported by epidemiological survey data. The sex-matched living spouse control design as an alternative control selection for a nationwide population-based case-control study is valid and feasible, and can produce highly acceptable research results for a fixed expenditure of time and resources.

\section{Acknowledgments}

We thank Cancer Research UK, the UK Medical Research Council, the US National Institutes of Health, the Chinese Ministry of Health, and the Chinese Academy of Medical Sciences who supported the original survey.

We thank Professor Richard Peto, who gave us great support for the project.

The cooperation of the local government, the thousands of doctors, nurses, and other field workers who conducted the surveys, and the million interviewees are greatly acknowledged.

\section{Conflict of Interest}

The authors have declared that no conflict of interest exists.

\section{References}

1. Liu $B Q$, Peto $R$, Chen $Z M$, et al. Emerging tobacco hazards in China 1. Retrospective proportional mortality study of one million deaths. Br Med J 1998; 317:1411-22.

2. Thun MJ, Apicella LF, Henley SJ. Smoking vs other risk factors as the cause of smoking-attributable deaths. JAMA 2000; 284:706-12.

3. Rivara FP, Ebel BE, Garrison MM, et al. Prevention of smoking-related deaths in the United States. Am J Prev Med 2004; 27:118-25.
4. Peto R, Lopez AD, Boreham J, et al. Mortality from tobacco in developed countries: indirect estimation from national vital statistics. Lancet 1992; 339:1268-78.

5. Sitas F, Urban M, Bradshaw D, et al. Tobacco attributable deaths in South Africa. Tobacco Control 2004; 13: 396-99.

6. Jiang J, Liu B, Sitas F, et al. Smoking-attributable deaths and potential years of life lost from a large, representative study in China. Tobacco control Sep 2009; [Epub ahead of print]..

7. Jones B, Jarvis $\mathrm{P}$, Lewis JA et al. Trail to assess equivalence: the importance of rigorous methods. BMJ 1996;313:36-39.

8. Greene WL, Concato J, Feinstein AR. Claims of Equivalence in Medical Research: Are They Supported by the Evidence? Ann Intern Med 2000; 132: 715-22.

9. Fuller RW, Hallett C, Dahl R. Assessing equivalence of inhaled drugs. Respir Med 1995; 89: 525-27.

10. Dong BJ, Hauck WW, Gambertoglio JG, et al. Bioequivalence of generic and brand-name levothyroxine products in the treatment of hypothyroidism. JAMA 1997; 277: 1205-13.

11. Wacholder S, Silverman DT, McLaughlin JK, et al. Selection of Controls in Case-Control Studies: III. Design Options. Am J Epidemiol 1992 135: 1042-50.

12. Lopez AD. Counting the dead in China. Measuring tobacco's impact in the developing world. Br Med J 1998, 317:1399-1400.

13. Schuirmann DJ. A comparison of the two one-sided tests procedure and the power approach for assessing the equivalence of average bioavailability. J Pharmacokinet Biopharm 1987; 15: 657-80.

14. Weng XZ. Report on the 1984 Chinese national smoking prevalence survey. Beijing: People's Medical Publishing House, 1988.

15. Yang GH. Report on the 1996 nationwide survey of smoking prevalence. Beijing: China Science and Technology Press, 1997.

16. Gu D, Wu X, Reynolds $\mathrm{K}$, et al. Cigarette smoking and exposure to environmental tobacco smoke in China: the international collaborative study of cardiovascular disease in Asia. Am J Public Health 2004; 4: 1972-6.

17. Deng J. The prevalence of smoking habit among 110000 adult residents in urban Shanghai [in Chinese]. Zhonghua Yu Fang Yi Xue Za Zhi 1985;5:271-4.

18. Dunnett CW, Gent M. Significance testing to establish equivalence between treatments, with special reference to data in the form of 2x2 tables. Biometrics 1977; 33: 593-602.

19. Bernard R Rosner. Fundamentals of Biostatistics. Brooks Cole; 2005.

20. Ibrahim MA, Spitzer WO. The case-control study: the problem and the prospect. J Chronic Dis 1979; 32: 139-44.

21. Horwitz RI, Feinstein AR. Alternative analytic endometrial cancer. N Engl J Med 1978; 299: 1089-94.

22. Hulka BS, Grimson RC, Greenberg BG, et al. "Alternative" controls in a case-control study of endometrial cancer and exogenous estrogen. Am J epidemiol 1980; 112: 376-387.

23. Boissel JP, Collet JP, Lion L, et al. A randomized comparison of the effect of four antihypertensive monotherapies on the subjective quality of life in previously untreated asymptomatic patients: field trial in general practice. The OCAPI Study Group. Optimiser le Choix d'un Anti-hypertenseur de Premiere Intention. J Hypertens 1995; 13: 1059-67. 


\section{Appendix}

Fig. 5. The procedure of calculating $95 \% \mathrm{Cl}$ for $\mathrm{RR}_{1} / \mathrm{RR}_{2}$

2 by 2 table with one group of case and two groups of controls

\begin{tabular}{llll}
\hline & Cases & Controls 1 & Controls 2 \\
Smoke & $\mathrm{a}$ & $\mathrm{b}_{1}$ & $\mathrm{~b}_{2}$ \\
Non-smoke & $\mathrm{c}$ & $\mathrm{d}_{1}$ & $\mathrm{~d}_{2}$ \\
\hline
\end{tabular}

1. From the 2 by 2 table described above, an estimated odds ratio $\left(\mathrm{OR}_{1}\right.$ or $\left.\mathrm{OR}_{2}\right)$ may be calculated respectively from the expression

$$
O \hat{R}_{1}=a d_{1} / b_{1} c, \quad O \hat{R}_{2}=a d_{2} / b_{2} c .
$$

2. Since $\ln O \hat{R}_{1}-\ln O \hat{R}_{2}=\ln \frac{O \hat{R}_{1}}{O \hat{R}_{2}}=\ln \left[\left(\frac{a d_{1}}{b_{1} c}\right) /\left(\frac{a d_{2}}{b_{2} c}\right)\right]=\ln \left(\frac{b_{2} d_{1}}{b_{1} d_{2}}\right)=-\ln \left(\frac{b_{1} d_{2}}{b_{2} d_{1}}\right)=-\ln O \hat{R}^{\prime}$,

and note that the distribution of the $\ln O \hat{R}^{\prime}$ is accurately approximated by a normal distribution, therefore, $\operatorname{lnO\hat {R}_{1}}-\ln O \hat{R}_{2}$ is also approximated by a normal distribution, i.e.,

$$
\operatorname{lnO\hat {R}_{1}}-\ln O \hat{R}_{2} \sim N\left[\mathrm{E}\left(\operatorname{lnO\hat {R}_{1}}-\ln O \hat{R}_{2}\right), \operatorname{Var}\left(\operatorname{lnO} \hat{\mathrm{R}}_{1}-\ln O \hat{R}_{2}\right)\right],
$$

where

$$
\mathrm{E}\left(\operatorname{lnO\hat {R}_{1}}-\ln O \hat{R}_{2}\right)=0 \text { (under Null Hypothesis). }
$$

According to the Cauchy- Schuarz inequality of mathematics,

$$
\operatorname{Var}\left(\ln O \hat{R}_{1}-\ln O \hat{R}_{2}\right) \leq 2\left[\operatorname{Var}\left(\ln O \hat{R}_{1}\right)+\operatorname{Var}\left(\ln O \hat{R}_{2}\right)\right]
$$

The estimated variance associated with the $\ln O \hat{R}_{1}$ or $\ln O \hat{R}_{2}$ is calculated from the expression

$$
\operatorname{Var}\left(\ln O \hat{R}_{1}\right)=\frac{1}{a}+\frac{1}{b_{1}}+\frac{1}{c}+\frac{1}{d_{1}}, \operatorname{Var}\left(\ln O \hat{R}_{2}\right)=\frac{1}{a}+\frac{1}{b_{2}}+\frac{1}{c}+\frac{1}{d_{2}} .
$$

3. $95 \% \mathrm{CI}$ for $\left(\operatorname{lnOR}_{1}-\ln O R_{2}\right)$ can be calculated from the formula by

$$
\operatorname{lnOR_{1}}-\ln O \hat{R}_{2} \pm 1.96 \sqrt{2\left[\operatorname{Var}\left(\ln O \hat{R}_{1}\right)+\operatorname{Var}\left(\ln O \hat{R}_{2}\right)\right]} .
$$

Taking the exponent, the $95 \% \mathrm{CI}$ for $\mathrm{OR}_{1} / \mathrm{OR}_{2}$ is

$$
\left(\frac{O \hat{R}_{1}}{O \hat{R}_{2}} e^{-1.96 \times \sqrt{2 \times\left(\operatorname{Var} O \hat{R}_{1}+\operatorname{Var} O \hat{R}_{2}\right)}}, \quad \frac{O \hat{R}_{1}}{O \hat{R}_{2}} e^{+1.96 \times \sqrt{2 \times\left(\operatorname{Var} O \hat{R}_{1}+\operatorname{Var} O \hat{R}_{2}\right)}}\right)
$$

Since $R \hat{R} \cong O \hat{R}$ in a case-control study, we can replace $O \hat{R}$ by $R \hat{R}$ expressed in the text. 